\title{
Caracterização de amostras atenuadas do vírus da Diarréia Viral Bovina (BVDV) tipos 1 e 2 para uso em vacinas ${ }^{1}$
}

\author{
Marcelo de Lima², Eduardo Furtado Flores ${ }^{3}$, Rudi Weiblen ${ }^{4}$, Fernanda Silveira \\ Flores Vogel ${ }^{5}$ e Sandra Arenhart ${ }^{6}$
}

\begin{abstract}
Lima M., Flores E.F., Weiblen R., Flores F.S.F. \& Arenhart S. 2004. [Characterization of bovine viral diarrhea virus (BVDV) types 1 and 2 isolates for use in vaccines.] Caracterização de amostras atenuadas do vírus da Diarréia Viral Bovina (BVDV) tipos 1 e 2 para uso em vacinas. Pesquisa Veterinária Brasileira 24(1):35-42. Depto Medicina Veterinária Preventiva, Centro de Ciências Rurais, Universidade Federal de Santa Maria, Santa Maria, RS 97105-900, Brazil. E-mail: flores@ccr.ufsm.br

This article reports the characterization of two cytopathic isolates of bovine viral diarrhea virus (BVDV-1: IBSP-2; BVDV-2:SV-253) submitted to multiple passages $(n=30)$ in tissue culture associated with ultraviolet irradiation. The vaccine candidate strains were characterized in vitro (plaque size and morphology, growth kinetics and antigenic profile) and in vivo (attenuation and serological response in calves). In vitro characterization of biologically cloned viruses obtained at passages $0,1,10,20$ and 30 demonstrated that the attenuation process did not significantly affect the phenotypic and antigenic properties of the viruses. No major differences in plaque size and morphology and in the growth kinetics in tissue culture were observed among the viruses obtained at different passages. Likewise, the antigenic profile of these viruses did not change upon successive passages in tissue culture, as ascertained by the pattern of binding by 48 monoclonal antibodies (mAbs). Intramuscular inoculation of both viruses (IBSP-2: $10^{7.3} \mathrm{TCID}_{50} ; \mathrm{SV}-253: 10^{6.8} \mathrm{TCID}_{50}$ ) at passage 30 (p30) in twelve 15 months old heifers did not produce clinical signs, demonstrating the attenuation of the viruses. Following inoculation, infectious virus was detected in leucocytes of most inoculated animals (10/12) between days 3 and 6 post-inoculation (pi) and in nasal secretions of three animals (days 4, 7 and $8 \mathrm{pi}$ ). However, the vaccine viruses were not transmitted to three seronegative calves maintained as sentinels. All vaccinated calves seroconverted at day 14 post-vaccination. A moderate to high serum neutralizing response against five Brazilian BVDV-1 (titers from 80 to $\geq 1,280$ ) and four Brazilian BVDV-2 isolates (titers from 20 to 640) was observed at day 33 postvaccination (pv). In general, the highest titers were observed against the Brazilian BVDV-1 isolates. At day 240 post-vaccination, the animals received a booster administration (IBSP-2: $10^{7.3} \mathrm{TCID}_{50}$ and SV-253: $10^{6.8} \mathrm{TCID}_{50}$ ). Revaccination resulted in a strong anamnestic response in most animals, with increasing antibody titers mainly to BVDV-2. These are promising results towards the future use of these strains in modified-live vaccines for the control of BVDV infection in Brazil .
\end{abstract}

INDEX TERMS: Bovine viral diarrhea virus (BVDV), modified-live vaccine, attenuation.

${ }^{1}$ Recebido em 3 de dezembro de 2003.

Aceito para publicação em 16 de dezembro de 2003.

Parte da dissertação de mestrado do primeiro autor apresentada ao Programa de Pós-graduação em Medicina Veterinária da Universidade Federal de Santa Maria (UFSM). Trabalho realizado com o suporte financeiro do MCT, CNPq, CAPES e FINEP (Pronex em Virologia Veterinária, 215/96).

${ }^{2}$ Médico Veterinário, aluno do Programa de Pós-graduação em Medicina Veterinária, UFSM.
3Departamento de Medicina Veterinária Preventiva, CCR, e Departamento
de Microbiologia e Parasitologia, Centro de Ciências da Saúde, UFSM. Bolsis-
ta CNPq (520758/96-0). DMVP/CCR/UFSM, 97105-900 Santa Maria, RS. Fone/
fax: (55) 220-8034. Autor para correspondência. E-mail: flores@ ccr.ufsm.br
'Depto Medicina Veterinária Preventiva, CCR, e Depto Microbiologia e
Parasitologia, Centro de Ciências da Saúde, UFSM. Bolsista CNPq (520161/97-1).
${ }^{5}$ Doutor em Medicina Veterinária.
${ }^{6}$ Estudante do curso de Medicina Veterinária, Bolsista CNPq/PIBIC/UFSM. 
RESUM 0.- Este artigo relata a caracterização de duas amostras cito páticas do vírus da Diarréia Viral Bovina (BVDV-1: IBSP2; BVDV-2: SV-253) submetidas à atenuação por múltiplas passagens em cultivo celular e exposição à radiação ultravioleta. As amostras foram caracterizadas in vitro (tamanho e morfologia de placas, cinética de replicação e perfil antigênico) e in vivo (atenuação e resposta sorológica em bovinos). A caracterização in vitro de populações clonadas dos vírus obtidas nas diferentes passagens em cultivo celular $(0,1,10,20$ e 30), demonstrou que o processo de atenuação não afetou negativamente as características antigênicas e fenotípicas das amostras. Não foram observadas alterações significativas no tamanho e morfologia de placas e na cinética de replicação. A reatividade com 48 anticorpos monoclonais demonstrou que o perfil antigênico não doi alterado durante as sucessivas passagens in vitro. A inoculação intramuscular dos clones de vírus obtidos na passagem 30 (IBSP-2: $10^{7,3} \mathrm{DICC}_{50} ; \mathrm{SV}$ 253: $10^{6,8} \mathrm{DICC}_{50}$ ) em 12 novilhas soronegativas com idade média de 15 meses, não resultou em sinais clínicos, comprovando sua atenuação. Após a inoculação, o vírus foi detectado em leucócitos da maioria dos animais inoculados (10/12) entre os dias 3 e 6 pós-inoculação (pi) e em secreções nasais de três animais (dias 4, 7 e 8pi). No entanto, não ocorreu transmissão dos vírus vacinais aos três animais soronegativos mantidos como sentinelas. Todos os animais vacinados soroconverteram aos 14 dias pós-vacinação (dpv). Títulos moderados a altos de anticorpos neutralizantes foram detectados frente a 5 isolados brasileiros do BVDV-1 (títulos de $80 \mathrm{a} \geq 1280$ ) e quatro isolados do BVDV-2 (títulos de 20 a 640). Em geral, os títulos foram de magnitude superior frente a isolados brasileiros do BVDV-1. Aos $240 \mathrm{dpv}$, os animais receberam uma segunda dose dos vírus vacinais (IBSP-2: $10^{7,3} \mathrm{DICC}_{50} ; \mathrm{SV}-253: 10^{6,8} \mathrm{DICC}_{50}$ ). A revacinação induziu uma resposta secundária na maioria dos animais, resultando em um aumento dos títulos de anticorpos neutralizantes principalmente frente ao BVDV-2. Esses resultados são promissores no sentido da utilização dessas amostras na formulação de vacinas atenuadas para o controle da infecção pelo BVDV no Brasil.

TERMOS DE INDEXAÇÃO: Vírus da Diarréia Viral Bovina (BVDV), vírus atenuado, vacinas.

\section{INTRODUÇÃO}

0 vírus da Diarréia Viral Bovina (Bovine viral diarrhea virus BVDV) é um dos patógenos mais importantes de bovinos. 0 BVDV é responsável por diversas manifestações clínicas e perdas econômicas em rebanhos de corte e leite em todo 0 mundo (Baker 1995). O BVDV é um vírus pequeno (40-60nm de diâmetro), classificado na família Flaviviridae, gênero Pestivirus. 0 material genético é uma molécula de RNA de cadeia simples, polaridade positiva, com aproximadamente $12,5 \mathrm{~kb}$. 0 vírus possui um nucleocapsídeo icosaédrico envolto por um envelope lipoprotéico contendo três glicoproteínas virais: gp48/E0, gp25/E1 e gp53/E2 (Donis 1995).

Variações na seqüência de nucleotídeos na região 5 ' não traduzida (5'UTR) do genoma permitiram a classificação do BVDV em dois genótipos: BVDV-1 e BVDV-2 (Ridpath et al. 1994). Além disso, tem sido proposta uma subclassificação de isolados do BVDV-1 em 11 subgenótipos (Vilcek et al. 2001) e do BVDV-2 em pelo menos dois subgrupos (Flores et al. 2002). Uma característica marcante dos Pestivirus é a existência dos biotipos citopático (CP) e não citopático (NCP), de acordo com o efeito da replicação do vírus em cultivo celular. A infecção de células permissivas pela maioria dos isolados de campo não produz efeito citopático (ECP). No entanto, amostras CP são isoladas de animais que desenvolvem a Doença das Mucosas (Lindenbach \& Rice 2001). A citopatologia em cultivo celular não possui correlação com a virulência em infecções agudas, sendo que os isolados virulentos do BVDV2 são NCP (Ridpath 2003a).

A infecção aguda de animais imunocompetentes pode resultar em enfermidade entérica, respiratória, hemorrágica ou infertilidade temporária. Quando fêmeas gestantes, soronegativas, são infectadas, o vírus possui a capacidade de atravessar a placenta e infectar o feto. Dependendo da fase de gestação, a infecção fetal pode resultar em mortalidade embrionária ou fetal, abortamento, mumificação, teratogenia ou o nascimento de bezerros fracos e inviáveis (Baker et al. 1995). A infecção de fêmeas entre os dias 40 e 120 de gestação com amostras NCP pode resultar na geração de bezerros persistentemente infectados (PI). Os animais PI excretam constantemente 0 vírus em altos títulos nas secreções e excreções, constituindo-se na principal fonte de manutenção e transmissão da infecção nos rebanhos (Baker 1995).

A infecção pelo BVDV está amplamente difundida no rebanho bovino brasileiro (Oliveira et al. 1996, Botton et al. 1998). Amostras dos dois genótipos e com diferenças genéticas e antigênicas marcantes das cepas americanas já foram identificadas no Brasil (Botton et al. 1998, Flores et al. 2002). Essa diversidade genética e antigênica possui implicações práticas para o diagnóstico, produção de vacinas e programas de controle da enfermidade (Flores et al. 2002, Ridpath 2003a).

A escol ha das estratégias mais adequadas para a profilaxia e controle da infecção pelo BVDV depende das condições específicas de cada rebanho (Houe 2003). Em geral, essas estratégias consistem na prevenção da entrada de animais PI e/ou remoção destes de uma propriedade, além da utilização de vacinas (Oirschot et al. 1999, Fulton \& Burge 2001). 0 principal objetivo da vacinação deve ser prevenir a infecção fetal e assim evitar a contínua geração de animais PI (Oirschot et al. 1999).

Nos Estados Unidos, as primeiras vacinas contra o BVDV surgiram na década de 60 sendo que, atualmente, estão disponíveis mais de 160 vacinas comerciais contendo imunógenos do BVDV (Ridpath 2003b). Essas vacinas contém cepas inativadas ou atenuadas do BVDV-1 e/ou BVDV-2 (Fulton et al. 2003a). No Brasil, somente são comercializadas vacinas inativadas, contendo cepas americanas do BVDV. Além disso, a maioria destas vacinas contém apenas amostras do genótipo 1. Estudos recentes demonstraram que essas vacinas induzem níveis baixos de anticorpos neutralizantes em ovinos e bovinos, principalmente contra amostras brasileiras de BVDV2 , além da incapacidade de conferir proteção fetal em oveIhas prenhes (Vogel et al. 2002). Nesse sentido, é evidente a 
necessidade da elaboração de vacinas que contenham amostras representativas dos isolados de campo brasileiros de ambos os genótipos e que induzam níveis adequados de anticorpos com amplo espectro antigênico.

0 objetivo do presente trabalho foi caracterizar duas amostras do BVDV-1 e BVDV-2 atenuadas experimentalmente. As amostras foram caracterizadas in vitro (perfil antigênico, cinética de replicação, tamanho e morfologia de placas) e in vivo (atenuação, magnitude e espectro de reatividade da resposta sorológica em bovinos).

\section{MATERIALE MÉTODOS}

Células e vírus. Os procedimentos de multiplicação, titulação e isolamento de vírus foram real izados em células da linhagem MDBK
(Madin Darby bovine kidney) cultivadas em MEM (meio essencial mínimo) contendo penicilina (1,6mg/L), estreptomicina $(0,4 \mathrm{mg} / \mathrm{L})$ e nistatina $(0,02 \mathrm{mg} / \mathrm{L})$ suplementadas com $5 \%$ de soro eqüino. Foram utilizados dois isolados CP do BVDV (IBSP-2 e SV-253) gentilmente cedidos pela Dra. Edviges Maristela Pituco (Instituto Biológico, SP) e pelo Dr. Fernando Osório (University of Nebraska, Lincoln, NE, USA).. Essas amostras foram caracterizadas em nível antigênico e molecular como sendo pertencentes aos genótipos 1 e 2 respectivamente (Botton et al. 1998, Flores et al. 2002). O procedimento utilizado para a obtenção das amostras atenuadas foi descrito por Brum et al. (2002). As amostras utilizadas na vacinação dos animais foram obtidas pela amplificação em cultura de células dos clones de vírus obtidos na passagem 30 (p30).

Perfil antigênico. Células MDBK infectadas com cada um dos clones de vírus purificados nas passagens $0,1,10,20$ e 30 foram

Quadro 1. Perfil de reatividade de anticorpos monoclonais com amostras atenuadas do vírus da Diarréia Viral Bovina (BVDV) tipos 1 e 2 obtidas por clonagem, em diferentes passagens em cultivo celular

\begin{tabular}{|c|c|c|c|c|c|c|c|c|c|c|c|c|c|c|c|c|c|c|c|c|c|c|c|c|c|}
\hline \multirow[t]{4}{*}{ Vírus/AcMs } & \multicolumn{25}{|c|}{ Especificidade protéica dos anticorpos monoclonais (AcMs) } \\
\hline & \multicolumn{25}{|c|}{ BVDV-1 } \\
\hline & \multicolumn{20}{|c|}{ gp53 } & \multicolumn{3}{|c|}{ gp48 } & \multicolumn{2}{|c|}{ p125 } \\
\hline & $1^{c}$ & 2 & $3^{d}$ & 4 & 5 & 6 & 7 & 8 & 9 & 10 & 11 & 12 & 13 & 314 & $415^{\epsilon}$ & e 16 & 17 & 18 & 19 & $20^{d}$ & 21 & 22 & & 23 & 24 \\
\hline Singerg & $+h$ & + & + & + & + & + & + & + & + & + & + & + & + & + & + & + & + & + & + & - & + & + & & + & + \\
\hline IBSP-2 ${ }^{j}$ & - & + & - & - & + & + & - & + & - & - & - & - & + & - & + & + & + & + & + & - & - & + & & + & + \\
\hline $1 \mathfrak{a} U V^{k}$ & + & + & - & - & - & + & - & + & + & - & - & - & + & - & + & + & + & + & + & - & - & + & & + & + \\
\hline 10a UVk & + & + & - & - & - & + & - & + & + & - & - & - & + & - & + & + & + & + & + & + & - & + & & + & + \\
\hline 20 a UVk & + & + & - & - & - & + & - & + & + & - & - & - & + & - & + & + & + & + & + & + & + & + & & + & + \\
\hline 30 a UVk & + & + & - & - & - & + & - & + & - & - & - & - & + & - & + & + & + & + & + & - & - & + & & + & + \\
\hline $890^{1}$ & + & + & - & - & - & - & - & - & - & - & - & - & + & + & + & + & + & + & - & - & - & + & & + & + \\
\hline SV-253j & + & + & - & - & - & - & - & - & - & - & - & - & + & + & + & + & + & + & - & + & - & + & & + & + \\
\hline $1 \mathfrak{a}$ UVk & + & + & - & - & - & - & - & - & - & - & - & - & + & + & + & + & + & + & - & + & - & + & & + & + \\
\hline 10 a UVk & + & + & - & - & - & - & - & - & - & - & - & - & + & + & + & + & + & + & - & + & - & + & & + & + \\
\hline 20 a UVk & + & + & - & - & - & - & - & - & - & - & - & - & + & + & + & + & + & + & - & + & - & + & & + & + \\
\hline \multirow[t]{4}{*}{30 a UVk } & + & + & - & - & - & - & - & - & - & - & - & + & + & + & + & + & + & + & - & + & - & + & & + & + \\
\hline & \multicolumn{11}{|c|}{ BVDV-1 ${ }^{a}$} & \multicolumn{14}{|c|}{ BVDV- $2^{\mathrm{b}}$} \\
\hline & \multicolumn{11}{|c|}{ Proteína não determinada } & \multicolumn{14}{|c|}{ gp53 } \\
\hline & 25 & 26 & 27 & 28 & 29 & 30 & 31 & 32 & 33 & 34 & 35 & & $36^{f}$ & 37 & 38 & 39 & 40 & 41 & 42 & 43 & 44 & 45 & 46 & 47 & 48 \\
\hline Singerg & + & + & + & + & + & + & + & + & + & - & + & & - & + & - & - & - & - & - & - & - & + & - & - & - \\
\hline IBSP-2 $2^{j}$ & + & - & - & - & - & - & - & + & + & - & + & & - & - & - & - & - & - & - & - & - & - & - & - & - \\
\hline $1 \stackrel{a}{a} U^{k}$ & - & - & - & - & - & - & - & + & + & - & + & & - & - & - & - & - & - & - & - & - & - & - & - & - \\
\hline $10^{a}$ UVk & - & - & - & - & - & - & - & + & + & - & + & & - & - & + & - & - & - & - & - & - & - & - & - & - \\
\hline 20 a UVk & - & - & - & - & - & - & - & + & + & - & + & & - & - & - & - & - & - & - & - & - & - & - & - & - \\
\hline 30 a UVk & + & - & - & - & - & - & - & + & + & - & + & & - & - & - & - & - & - & - & - & - & - & - & - & - \\
\hline $890^{\prime}$ & - & - & - & - & - & - & - & + & - & - & - & & + & + & + & + & + & + & + & + & + & + & + & + & + \\
\hline SV-253j & - & - & - & - & - & - & - & - & - & + & - & & + & + & + & + & + & - & + & + & + & + & + & + & + \\
\hline $1 \stackrel{a}{a} U^{k}$ & - & - & - & - & - & - & - & - & - & - & - & & + & + & + & + & + & - & + & + & + & + & + & + & + \\
\hline 10a UVk & - & - & - & - & - & - & - & + & - & - & + & & + & + & + & + & + & - & + & + & + & + & + & + & + \\
\hline 20 a UVk & - & - & - & - & - & - & - & + & - & - & + & & + & + & + & + & + & + & + & + & + & + & + & + & + \\
\hline 30 a UVk & - & - & - & - & - & - & - & + & - & - & + & & + & + & + & + & + & - & + & + & + & + & + & + & + \\
\hline
\end{tabular}

acMs produzidos contra o BVDV-1.

${ }^{b}$ AcMs produzidos contra o BVDV-2.

CAcMs (1-2): Kreutz et al. 2000.

dACMs (3-14; 20-35): Corapi et al. 1990.

eAcMs (15-19): Bolin et al. 1988

${ }^{f}$ AcMs (36-48): Deregt et al. 1998.

gAmostra de referência do BVDV-1.

h(+) Reação positiva na técnica de imunofluorescência indireta.

i (-) Reação negativa na técnica de imunofluorescência indireta.

jAmostra original sem exposição à radiação UV.

k Clone de vírus obtido após passagem em cultivo celular e exposição à radiação UV.

'Amostra de referência do BVDV-2. 
submetidas à imunofluorescência indireta (IFI) de acordo com a técnica descrita por Botton et al. (1998). Para isso, foram utilizados 48 anticorpos monoclonais (AcMs) produzidos contra glicoproteínas do envelope, proteínas não-estruturais e outros de especificidade protéica não determinada do BVDV (Quadro 1). Células MDBK infectadas com as cepas padrão Singer (BVDV-1) ou 890 (BVDV-2) e células não infectadas foram utilizadas como controles positivos e negativos, respectivamente.

Cinética de replicação. Os clones de vírus obtidos nas passagens $0,1,10,20$ e 30 foram inoculados em monocamadas de células MDBK com multiplicidade de infecção de 0,1 DICC $_{50} /$ célula (dose infectante para 50\%dos cultivos celulares). Após 1 h de adsorção, o inóculo foi removido, a monocamada de células lavada três vezes com MEM, acrescentando-se meio de cultivo suplementado com soro eqüino. Alíquotas de $250 \mathrm{~mL}$ foram coletadas em diferentes interval os $(1,10$, $15,20,24,36,48$ e 60 h pós-inoculação) e tituladas através do método de diluição limitante e os títulos expressos de acordo com Reed \& Müench (1938).

Tamanho e morfologia de placas. Para a observação do tamanho e morfologia de placas, os clones obtidos nas referidas passagens foram submetidos a técnica de ensaio de placa, conforme descrito por Botton et al. (1998).

Inocuidade para bovinos. Foram utilizadas 15 novilhas mestiças com idade média de 15 meses, soronegativas para o BVDV. Doze animais foram inoculados pela via intramuscular (IM) com $1 \mathrm{~mL}$ de cada amostra viral (IBSP-2: 107,3 DICC $_{50}$ e SV-253: $10^{6,8}$ DICC $_{50}$ ). Três animais permaneceram como sentinelas, em contato com os animais inoculados. Após a inoculação, os animais foram monitorados clinicamente durante 14 dias e submetidos à coleta diária de sangue e secreções nasais para verificação da replicação e excreção viral. Aos 240 dias pós vacinação (dpv) os animais receberam uma segunda dose das amostras vacinais (IBSP-2: $10^{7,3}$ DICC $_{50} / \mathrm{mL}$ e SV253: $10^{6,8}$ DICC $_{50} / \mathrm{mL}$ ) pela via IM. Aos $270 \mathrm{dpv}$, realizou-se uma nova coleta de sangue para avaliação da resposta sorológica secundária.

Pesquisa de vírus. 0 material proveniente dos swabs nasais ou da capa flogística foi inoculado em monocamadas de células MDBK e os cultivos foram monitorados por três passagens consecutivas de $72 \mathrm{~h}$ cada para verificação do efeito citopático (ECP). No final da tercei ra passagem, as células inoculadas foram submetidas à técnica de IFI para a possível detecção de antígenos virais.

Sorologia. Para a avaliação da resposta sorológica aos vírus vacinais inoculados, utilizou-se a técnica de soroneutralização (SN) conforme descrito por Botton et al. (1998). A resposta sorológica foi avaliada frente às amostras homólogas nos dias 7, 14, 21, 33, 240 e 270 pós-vacinação (pv). Com o soro coletado no dia 33pv, avaliou-se a resposta sorológica cruzada frente à cepas de referência e diferentes isolados brasileiros do BVDV-1 (Singer, NADL, SV-126.1, SV-126.8, SV-216/02, IBSP-4 e UFSM-1) e do BVDV-2 (890, Soldan, 34-B, SV-63 e SV-260). 0 título neutralizante foi considerado a recíproca da maior diluição capaz de prevenir a replicação viral. As médias dos títulos de anticorpos dos animais vacinados foram expressas em títulos médios geométricos (GMT) (Thrusfield 1986).

\section{RESULTADOS}

Perfil antigênico. 0 perfil de reatividade de 48 AcMs com os clones das amostras (IBSP-2 e SV-253) obtidos nas diferentes passagens em cultivo celular está apresentado no Quadro 1. Pequenas variações de reatividade com alguns AcMs foram observadas entre os clones de diferentes passagens. No entanto, o perfil de reatividade com a maioria dos AcMs permaneceu muito semelhante.
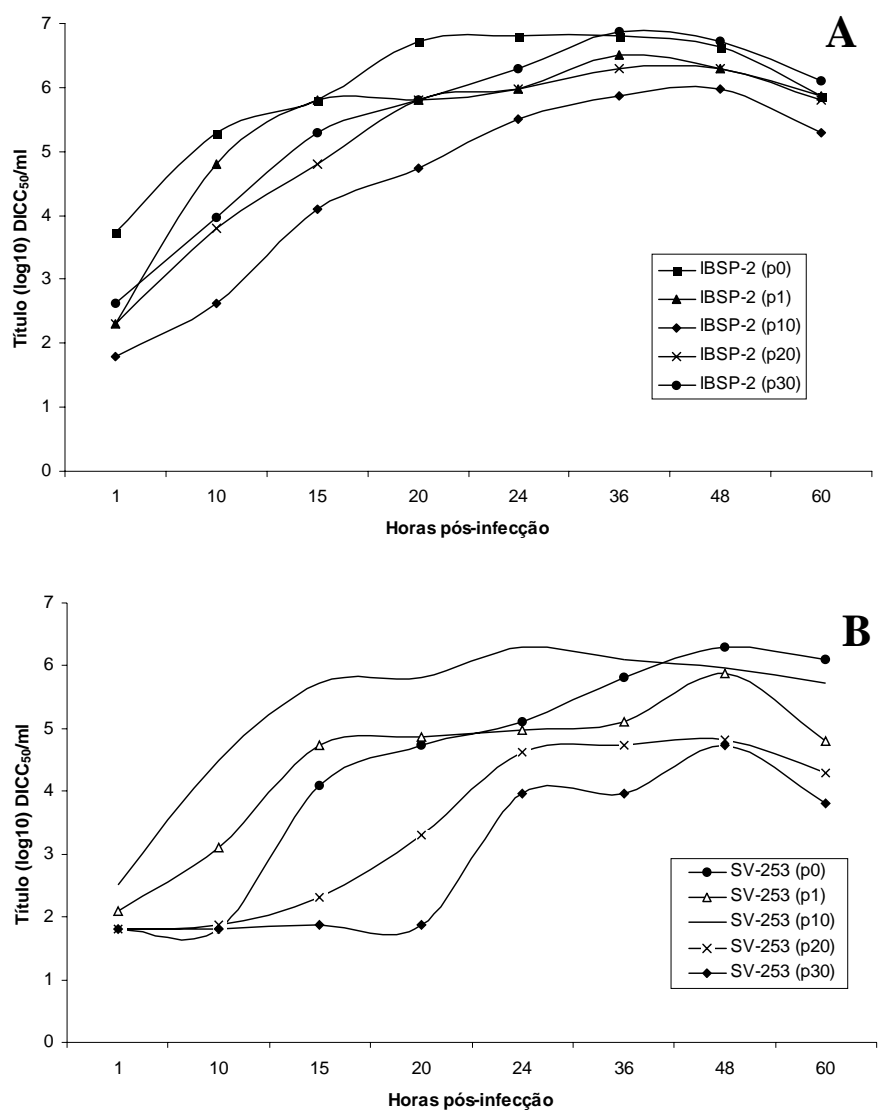

Fig. 1. Cinética de replicação das amostras vacinais clonadas obtidas em diferentes passagens em cultivo celular. IBSP-2 (A) e SV253 (B).

Quadro 2. Isolamento de vírus de secreções nasais e leucócitos de bovinos inoculados com uma vacina experimental contendo duas amostras atenuadas do vírus da Diarréia Viral Bovina (BVDV)

\begin{tabular}{|c|c|c|c|c|c|c|c|c|}
\hline \multirow{2}{*}{$\begin{array}{c}\text { Animal } \\
\text { no }\end{array}$} & \multicolumn{8}{|c|}{ Dia pós-inoculação (dpi) } \\
\hline & $1-2$ & 3 & 4 & 5 & 6 & 7 & 8 & $9-14$ \\
\hline
\end{tabular}

\begin{tabular}{|c|c|c|c|c|c|c|c|c|}
\hline \multicolumn{9}{|l|}{ Vacinados } \\
\hline 51 & $-a$ & - & $+{ }^{b}(I c)^{c}$ & - & - & $+(s n)^{d}$ & - & - \\
\hline 52 & - & - & - & - & - & - & - & - \\
\hline 53 & - & $+(I C)$ & - & - & - & - & - & - \\
\hline 54 & - & $+(\mathrm{IC})$ & - & - & - & - & - & - \\
\hline 91 & - & $+(I c)$ & - & - & - & - & - & - \\
\hline 92 & - & - & $+(I c)$ & - & $+(I c)$ & - & - & - \\
\hline 93 & - & $+(I c)$ & - & - & - & - & - & - \\
\hline 94 & - & - & - & - & - & - & - & - \\
\hline 95 & - & - & $+(I c)$ & - & $+(I c)$ & - & $+(s n)$ & - \\
\hline 96 & - & - & - & $+(I C)$ & $+(I c)$ & - & - & - \\
\hline 97 & - & $+(\mathrm{IC})$ & $+(s n)$ & - & - & $+(\mathrm{sn})$ & - & - \\
\hline 98 & - & - & - & $+(I c)$ & - & - & - & - \\
\hline \multicolumn{9}{|l|}{ Controles } \\
\hline 45 & - & - & - & - & - & - & - & - \\
\hline 46 & - & - & - & - & - & - & - & - \\
\hline 47 & - & - & - & - & - & - & - & - \\
\hline
\end{tabular}

aNegativo para vírus.

bpositivo para vírus.

$\mathrm{C}_{\mathrm{C}}=$ leucócitos.

$\mathrm{d}_{\mathrm{Sn}}=$ secreção nasal. 
Quadro 3. Títulos de anticorpos neutralizantes no soro de bovinos imunizados com uma vacina experimental contra o vírus da Diarréia Viral Bovina (BVDV)

\begin{tabular}{|c|c|c|c|c|c|c|c|c|c|c|c|c|}
\hline \multirow{3}{*}{$\begin{array}{c}\text { Animal } \\
\text { no }\end{array}$} & \multicolumn{12}{|c|}{ Dias pós-vacinação } \\
\hline & \multicolumn{2}{|c|}{7} & \multicolumn{2}{|c|}{14} & \multicolumn{2}{|c|}{21} & \multicolumn{2}{|c|}{33} & \multicolumn{2}{|c|}{$240^{b}$} & \multicolumn{2}{|c|}{270} \\
\hline & IBSP-2 & SV-253 & IBSP-2 & SV-253 & IBSP-2 & SV-253 & IBSP-2 & SV-253 & IBSP-2 & SV-253 & IBSP-2 & SV-253 \\
\hline \multicolumn{13}{|c|}{ Vacinados } \\
\hline 51 & $<5$ & $<5$ & 320 & 20 & 1280 & 40 & 2560 & 320 & 640 & 20 & 1280 & 160 \\
\hline 52 & $<5$ & $<5$ & 160 & 20 & 640 & 80 & 2560 & 160 & 1280 & 80 & 2560 & 640 \\
\hline 53 & $<5$ & $<5$ & 160 & 20 & 1280 & 40 & 2560 & 160 & 1280 & 40 & 2560 & 160 \\
\hline 54 & $<5$ & $<5$ & 80 & 20 & 640 & 40 & 1280 & 160 & 640 & 40 & 2560 & 320 \\
\hline 91 & $<5$ & $<5$ & 160 & 40 & 1280 & 40 & 2560 & 160 & 1280 & 80 & 2560 & 160 \\
\hline 92 & $<5$ & $<5$ & 20 & 5 & 320 & 40 & 640 & 80 & 640 & 80 & 2560 & 640 \\
\hline 93 & $<5$ & $<5$ & 80 & 20 & 640 & 40 & 1280 & 160 & 1280 & 160 & 5120 & 640 \\
\hline $94^{c}$ & $<5$ & $<5$ & 80 & 5 & 320 & 10 & 640 & 40 & 640 & 40 & $n t^{d}$ & $n t^{d}$ \\
\hline 95 & $<5$ & $<5$ & 160 & 20 & 640 & 80 & 2560 & 320 & 1280 & 40 & 5120 & 320 \\
\hline 96 & $<5$ & $<5$ & 80 & 40 & 320 & 80 & 640 & 80 & 320 & 40 & 640 & 160 \\
\hline 97 & $<5$ & $<5$ & 640 & 40 & 2560 & 80 & 5120 & 320 & 2560 & 320 & 10240 & 1280 \\
\hline 98 & $<5$ & $<5$ & 40 & 5 & 320 & 40 & 1280 & 160 & 640 & 20 & 2560 & 320 \\
\hline \multicolumn{13}{|c|}{ Controles } \\
\hline 45 & $<5$ & $<5$ & $<5$ & $<5$ & $<5$ & $<5$ & $<5$ & $<5$ & $<5$ & $<5$ & $<5$ & $<5$ \\
\hline 46 & $<5$ & $<5$ & $<5$ & $<5$ & $<5$ & $<5$ & $<5$ & $<5$ & $<5$ & $<5$ & $<5$ & $<5$ \\
\hline 47 & $<5$ & $<5$ & $<5$ & $<5$ & $<5$ & $<5$ & $<5$ & $<5$ & $<5$ & $<5$ & $<5$ & $<5$ \\
\hline
\end{tabular}

a Títulos frente às amostras homólogas expressos como a recíproca da maior diluição capaz de inibir a replicação viral.

bDia da revacinação.

cNão recebeu a dose de reforço aos $240 \mathrm{dpv}$.

eAmostra não testada.

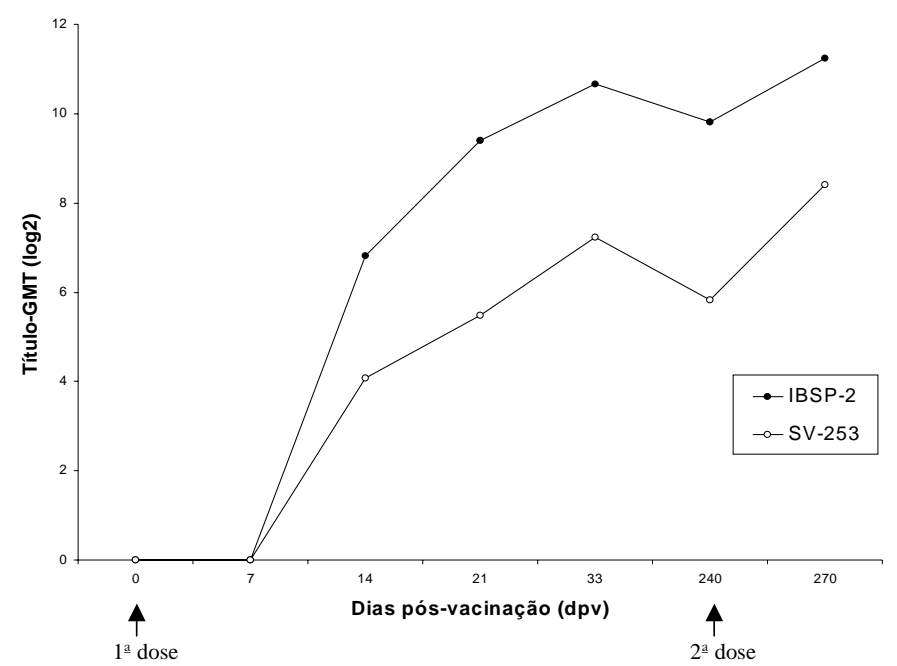

Fig. 2. Evolução dos títulos de anticorpos neutralizantes frente às amostras homólogas no soro de bovinos imunizados com uma vacina experimental contra o vírus da Diarréia Viral Bovina (BVDV). Títulos expressos em média geométrica (GMT).

Tamanho e morfologia de placas. Não foram observadas alterações significativas no tamanho ou morfologia das placas produzidas pelos vírus clonados obtidos nas diferentes passagens (resultados não mostrados). Observou-se apenas uma redução discreta no tamanho das placas formadas pela amostra SV-253 na passagem 20 (p20). No entanto, em passagens subseqüentes, observou-se a formação de placas de tamanho e morfologia semelhantes à amostra original .

Cinética de replicação. Os resultados do estudo da cinética de replicação dos vírus clonados estão apresentados na Figura 1. 0 clone obtido da amostra IBSP-2 apresentou títulos inferiores à amostra original quando examinado na passagem 10 (p10). No entanto, os títulos foram superiores a partir da p20, observando-se títulos semelhantes aos obtidos com a amostra original. Os clones da amostra SV-253 apresentaram redução nos títulos na p1, aumento na p10 e novamente redução nas passagens posteriores quando comparados com a amostra original. Em passagens subseqüentes foram obtidos títulos de $10^{7,3} \mathrm{DICC}_{50} /$ $\mathrm{mL}$ com a amostra IBSP-2 e $10^{6,8} \mathrm{DICC}_{50} / \mathrm{ml}$ com a amostra SV253.

Inocuidade para bovinos. Os vírus amplificados a partir dos clones obtidos na p30 não produziram sinais clínicos nos animais inoculados. Observou-se apenas uma elevação discreta na temperatura retal no dia 4 pós-inoculação (pi). Detectou-se vírus nos leucócitos de dez dos doze animais inoculados, entre os dias 3 e 6 pi, com um período de viremia máximo de dois dias (Quadro 2). A presença de vírus nas secreções nasais foi detectada inicialmente no animal no 97 (4 e $7 \mathrm{dpi}$ ) e nos animais no 51 e 95 aos 7 e 8dpi, respectivamente. A presença de vírus nos leucócitos e em secreções nasais dos animais inoculados indicam que houve replicação eficiente. Esses resultados demonstraram que os vírus inoculados replicaram eficientemente e apresentaram atenuação satisfatória para bovinos. Não detectou-se vírus nos leucócitos e em secreções nasais dos animais sentinelas mantidos em contato, demonstrando que não houve transmissão dos vírus vacinais a esses animais.

Resposta sorológica. Os resultados dos testes sorológicos realizados nos animais vacinados estão apresentados na Figura 2 e Quadros 3 e 4. Anticorpos neutralizantes foram de- 
Marcelo de Lima et al.

Quadro 4. Títulos de anticorpos neutralizantes no soro de bovinos imunizados com uma vacina experimental atenuada contra o vírus da Diarréia Viral Bovina (BVDV), frente à cepas de referência e isolados brasileiros do BVDVa,b

\begin{tabular}{|c|c|c|c|c|c|c|c|c|c|c|c|c|}
\hline \multirow{3}{*}{$\begin{array}{c}\text { Animalc } \\
n \underline{0}\end{array}$} & \multicolumn{7}{|c|}{ BVDV-1 } & \multicolumn{5}{|c|}{ BVDV-2 } \\
\hline & \multicolumn{2}{|c|}{ Refer. $^{d}$} & \multicolumn{5}{|c|}{ Isolados brasileiros } & \multirow{2}{*}{$\frac{\text { Refer. }^{\mathrm{e}}}{890}$} & \multicolumn{4}{|c|}{ Isolados brasileiros } \\
\hline & Singer & NADL & 126.1 & 126.8 & 1BSP-4 & $1216 / 02$ & UFSM-1 & & SV63 & Soldan & $34 \mathrm{~B}$ & SV 260 \\
\hline 51 & 320 & 160 & 80 & 640 & 320 & 160 & 640 & 40 & 40 & 40 & 160 & 40 \\
\hline 52 & 160 & 160 & 80 & 320 & 160 & 160 & 320 & 80 & 40 & 80 & 40 & 40 \\
\hline 53 & 80 & 160 & 320 & 640 & 320 & $\geq 1280$ & 640 & 80 & 80 & 40 & 20 & 40 \\
\hline 54 & 80 & 160 & 80 & 320 & 160 & 160 & 160 & 20 & 40 & 80 & 40 & 40 \\
\hline 91 & 320 & 320 & 80 & 640 & 320 & 320 & 160 & 20 & 80 & 40 & 40 & 40 \\
\hline 92 & 160 & 80 & 80 & 320 & 80 & 160 & 80 & 20 & 160 & 40 & 80 & 40 \\
\hline 93 & 160 & 80 & 80 & 640 & 160 & 160 & 160 & 20 & 40 & 80 & 40 & 80 \\
\hline 94 & 320 & 80 & 160 & 320 & 160 & 320 & 160 & 40 & 40 & 40 & 20 & 20 \\
\hline 95 & 320 & 640 & 160 & 160 & 320 & $\geq 1280$ & 640 & 40 & 160 & 80 & 80 & 40 \\
\hline 96 & 160 & 160 & 80 & 160 & 80 & 320 & 80 & 40 & 40 & 20 & 40 & 20 \\
\hline 97 & $\geq 1280$ & 320 & 640 & $\geq 1280$ & 640 & $\geq 1280$ & $\geq 1280$ & 160 & 640 & 320 & 640 & 320 \\
\hline 98 & 320 & 160 & 80 & 320 & 160 & 320 & 160 & 40 & 40 & 40 & 40 & 20 \\
\hline
\end{tabular}

Recíproca da maior diluição do soro capaz de inibir a replicação viral.

bSoro coletado no dia 33 pós-vacinação.

'Os animais controle apresentaram títulos inferiores a 5.

dCepa de referência do BVDV-1.

eCepa de referência do BVDV-2.

tectados aos 14dpv em todos os animais inoculados, sendo que aos 33dpv os animais possuíam títulos moderados a altos, principalmente frente à amostra IBSP-2 (GMT $=1612,7)$ e isolados brasileiros do BVDV-1. Por ocasião da segunda imunização (240dpv), os animais ainda possuíam títulos altos de anticorpos neutralizantes frente à amostra homóloga do BVDV-1 (GMT=905) e títulos moderados frente à amostra homóloga do BVDV-2 $(G M T=56,6)$. A revacinação induziu resposta secundária na maioria dos animais, com um aumento dostítulos de anticorpos, principalmente contra o BVDV-2 aos $270 \mathrm{dpv}$. Trinta dias após o reforço, todos os animais apresentavam títulos altos $(\geq 640)$ contra o BVDV-1 (GMT= 2416,3) e moderados $(\geq 160)$ contra o BVDV$2(\mathrm{GMT}=340)$.

\section{DISCUSSÃO}

Apesar dos esforços realizados para o controle e erradicação do BVDV nos Estados Unidos e Europa, o impacto econômico da infecção em rebanhos de corte e leite ainda é significativo. Estudos realizados para estimar o impacto econômico da infecção pelo BVDV em rebanhos leiteiros indicam que as perdas situam-se entre 10 e 40 dólares por terneiro nascido (Houe 2003). O sucesso limitado dos programas de controle deve-se, principalmente à grande variabilidade antigênica do vírus e ao surgimento de cepas altamente virulentas (Ridpath 2003a). A análise antigênica de amostras brasileiras do vírus e testes de vacinas comerciais demonstraram a necessidade da reformulação dos imunógenos do BVDV utilizados em vacinas no Brasil (Botton et al. 1998, Flores et al. 2002, Vogel et al. 2002).

0 objetivo principal da vacinação deve ser a indução de uma resposta imunológica capaz de prevenir a infecção fetal. No entanto, a grande maioria das vacinas não são eficazes nesse aspecto (Oirschot et al. 1999). Diversos estudos avaliando a imunogenicidade e proteção fetal conferidas por diversos tipos de vacinas, têm demonstrado diferentes graus de eficácia (Cortese et al. 1998a, Bruschke et al. 1999, Beer et al. 2000; Fulton \& Burgue 2001, Hamers et al. 2002, Zimmer et al. 2002, Fulton et al. 2003b).

No presente estudo, a caracterização in vitro demonstrou que as amostras utilizadas na vacinação dos animais (p30) eram muito semelhantes às amostras originais, indicando que o procedimento de atenuação não alterou as características antigênicas e fenotípicas das amostras.

A inoculação intramuscular das amostras vacinais em novilhas soronegativas, não resultou em sinais clínicos. Verificou-se apenas uma elevação discreta na temperatura retal no dia 4pi. Esses resultados demonstraram que a atenuação das amostras vacinais para bovinos jovens foi satisfatória. Entretanto, não se pode atribuir a atenuação das amostras vacinais ao processo utilizado para a obtenção das mesmas, uma vez que a virulência das amostras originais não foi testada em animais (Brum et al. 2002).

A imunização de ovelhas com as mesmas amostras, porém na p17 (IBSP-2) e p20 (SV-253), induziu uma resposta imunológica que foi capaz de prevenir a infecção fetal após o desafio intranasal com amostras heterólogas do BVDV tipos 1 e 2 (Brum et al. 2002). No entanto, as amostras mantiveram a capacidade de infecção transplacentária e por isso não seriam recomendadas para uso em fêmeas prenhes (Brum et al. 2002). Embora os ovinos sejam considerados bons modelos para estudar-se diversos aspectos da infecção e imunidade pelo BVDV (Scherer et al. 2001, Brum et al. 2002), estudos similares devem ser conduzidos em vacas prenhes, com o objetivo de verificar a segurança dessas amostras vacinais para fetos bovinos, assim como a capacidade de prevenção da infecção fetal frente à desafio.

No presente estudo, detectou-se vírus nos leucócitos da maioria dos animais vacinados (10/12) entre os dias 3 e 6 pósvacinação. A presença de vírus em secreções nasais foi detectada por um período curto e em apenas três animais. Do ponto de vista de segurança, é importante ressaltar que nenhum ani- 
mal sentinela soroconverteu durante o experimento. Além da ausência de sinais clínicos nos animais inoculados, não houve transmissão dos vírus vacinais aos animais mantidos em contato.

Avaliando-se a resposta humoral induzida por vacinas inativadas comercializadas no Brasil, observou-se que uma parcela significativa dos animais não respondeu à vacinação. Além disso, os títulos neutralizantes foram muito variáveis e de curta duração na maioria dos animais (Vogel et al. 2002). Neste trabalho, todos os animais apresentaram anticorpos neutralizantes no dia 14 pv. No dia 33pv, os títulos neutralizantes situavam-se entre 640 e $5120(\mathrm{GMT}=1612,7)$ para a amostra IBSP-2 e entre 40 e 320 (GMT = 151) para a amostra SV-253 aos 33dpv. Nesta data, os animais apresentavam títulos moderados a altos de anticorpos neutralizantes frente à diferentes isolados do BVDV-1 (80 até $\geq 1280$ ) e títulos de magnitude inferior frente às amostras brasileiras do BVDV-2 (20 até 640). Isso pode ser explicado, em parte, pelo fato da amostra vacinal SV-253 ser um isolado norte americano e que provavelmente possua diferenças antigênicas em relação às amostras brasileiras de BVDV-2. Os títulos inferiores contra as amostras do BVDV-2 (e mesmo contra a amostra homóloga) podem ser devidos também a uma capacidade inferior de replicação da amostra SV-253 in vivo, em relação à amostra IBSP-2. Além disso, nas duas imunizações, o título da amostra SV-253 utilizado foi inferior ao da amostra IBSP-2. De qualquer modo, os títulos de anticorpos neutralizantes foram muito superiores e o espectro de reatividade com isolados de campo foi mais amplo do que os induzidos por vacinas inativadas (Vogel et al. 2002).

No dia da revacinação (240dpv), todos os animais ainda apresentavam títulos de anticorpos neutralizantes (IBSP-2: $\mathrm{GMT}=905 ; \mathrm{SV}-253: \mathrm{GMT}=56,6)$. 0 teste do soro coletado aos 270dpv demonstrou que a revacinação induziu resposta secundária na maioria dos animais, refletindo-se na elevação dos títulos de anticorpos. Nesta data, os títulos médios foram GMT=2416,3 (IBSP-2) e GMT=340,8 (SV-253). Uma resposta anamnéstica mais intensa foi observada frente ao BVDV2. Isso deve-se, provavelmente, ao fato de que os títulos neutralizantes contra o BVDV-2 no momento da revacinação eram de magnitude inferior. Com isso, teriam sido insuficientes para prevenir a replicação da cepa vacinal homóloga, resultando em replicação do vírus vacinal e conseqüentemente em reestimulação do sistema imunológico.

Por outro lado, os altos títulos neutralizantes contra a amostra IBSP-2 no dia do reforço poderiam ter inibido a replicação do vírus homólogo e a indução de uma resposta secundária mais significativa. Avaliando a resposta sorológica induzida por vacinas inativadas contra o BVDV, Fulton \& Burge (2001) observaram que títulos neutralizantes $\geq 128$ geralmente inibem a elevação dos níveis de anticorpos após a revacinação. Embora a relação entre títulos de anticorpos neutralizantes e proteção frente ao desafio, ainda seja questionável (Oirschot et al.1999), é importante ressaltar que no dia 270 pós-vacinação (30 dias após o reforço) todos os animais possuiam títulos $\geq 640$ para o BVDV-1 e $\geq 160$ para o BVDV-2.

No Brasil, atualmente só existem vacinas comerciais inativadas para o BVDV. Entretanto, tem sido demonstrado que vacinas atenuadas induzem uma resposta imunológica mais sólida e duradoura (Cortese et al. 1998b). A utilização dessas vacinas, no entanto, pode resultar em infecção transplacentária, imunossupressão nos animais vacinados e manter virulência residual (Oirschot 1999), além da possibilidade de recombinação com vírus NCP e a indução da Doença das Mucosas em animais com infecção persistente (Ridpath \& Bolin 1995). Não obstante esses riscos, vacinas atenuadas podem ser administradas com segurança desde que sejam observadas rigorosamente as indicações do fabricante.

O objetivo principal da vacinação contra o BVDV é prevenir a infecção transplacentária e impedir a geração de animais PI. Nesse sentido, o uso de vacinas atenuadas parece ser uma boa alternativa, visto que já foi demonstrada proteção fetal completa em ovinos (Brum et al. 2002) e em bovinos (Frey et al. 2002). Porém, faz-se necessário a realização de experimentos adicionais para avaliar a capacidade dessas amostras vacinais de conferir proteção fetal em vacas prenhes.

Em resumo, as observações mais importantes desse estudo foram: (1) 0 procedimento utilizado para a atenuação não interferiu negativamente no fenótipo das amostras vacinais; (2) As amostras foram suficientemente atenuadas para bovinos e não foram transmitidas aos animais sentinelas; (3) Houve replicação eficiente em bovinos após a inoculação intramuscular; (4) A inoculação induziu títulos moderados a altos de anticorpos neutralizantes frente às amostras homólogas e isolados brasileiros, principalmente do BVDV-1; (5) Os títulos neutralizantes mantiveram-se em todos os animais até 8 meses após a primovacinação; (6) A revacinação induziu uma resposta secundária, principalmente frente ao BVDV-2, resultando em títulos altos de anticorpos neutral izantes em todos os animais. Esses resultados são promissores no sentido da utilização dessas amostras em vacinas atenuadas contra o BVDV.

\section{REFERÊNCIAS}

Baker J.C. 1995. The clinical manifestations of bovine viral diarrhea infection. Vet. Clin. North Am. 11(3):425-446.

Beer M., Hehnen H.R., Wolfmeyer A., Poll G., Kaaden O.R. \& Wolf G. 2000. A new inactivated BVDV genotype I and II vaccine. An immunization and challenge study with BVDV genotype I. Vet. Microbiol. 77:195-208.

Bolin S., Moenning V., Kelso Gourley N.E. \& Ridpath J. 1988. Monoclonal antibodies with neutralizing activity segregate isolates of bovine viral diarrhea virus into groups. Arch. Virol. 99:117-123.

Botton S. A., Silva A.M., Brum M.C.S., Weiblen R. \& Flores E.F. 1998. Antigenic characterization of Brazilian bovine viral diarrhea virus isolates by monoclonal antibodies and cross-neutralization. Braz. J. Med. Biol. Res. 31(11):1429-1438.

Brum M.C.S., Weiblen R., Flores E.F., Pituco E.M., Tobias F.L. \& Winkelmann E.R. 2002. Proteção fetal frente a desafio com o vírus da Diarréia Viral Bovina (BVDV) em ovelhas imunizadas com duas amostras de vírus modificadas experimentalmente. Pesq. Vet. Bras. 22 (2):64-72.

Bruschke C.J.M., van Oirschot J.T. \& van Rijn P.A. 1999. An experimental multivalent bovine virus diarrhea virus E2 subunit vaccines and two experimental conventionally inactivated vaccines induce partial fetal protection in sheep. Vaccine 17:1983-1991.

Corapi W.V., Donis R.O. \& Dubovi E.J. 1990. Characterization of a panel of monoclonal antibodies and their use in the study of the antigenic diversity of bovine viral diarrhea virus. Am. J. Vet. Res. 51(9):13881394. 
Cortese V.S., Grooms D.L., Ellis J., Bolin S.R., Ridpath J. \& Brock K.V. 1998a. Protection of pregnant cattle and their fetuses against infection with bovine viral diarrhea virus type 1 by use of a modified-live virus vaccine. Am. J. Vet. Res. 59(11):1409-1413.

Cortese V.S., Whittaker R., Ellis J., Ridpath J.F. \& Bolin S.R. 1998b. Specificity and duration of neutralizing antibodies induced in healthy cattle after administration of a modified-live vírus vaccine against bovine viral diarrhea. Am. J. Vet. Res.. 59(7):848-850.

Deregt D., van Rijn P.A., Wiens T.Y. \& van den Hurk J. 1998. Monoclonal antibodies to the E2 protein of a new genotype (type 2) of bovine viral diarrhea virus define three antigenic domains involved in neutralization. Virus Res. 57:171-181.

Donis R.O. 1995. Molecular biology of bovine viral diarrhea virus and its interactions with the host. Vet. Clin. North Am. 11(3):393-423.

Flores E.F., Ridpath J., Weiblen R., Vogel F.S.F. \& Gil L.H.V.G. 2002. Phylogenetic analysis of Brazilian bovine viral diarrhea virus type 2 (BVDV-2) isolates: evidence for a subgenotype within BVDV-2. Virus Res. 87:51-60.

Frey H.R., Eicken K., Grummer B., Kenklies S., Oguzoglu T.C. \& Moenning V. 2002. Foetal protection against bovine viral diarrhea virus after twostep vaccination. J. Vet. Med. B 49 (10):489-493.

Fulton R.W. \& Burge L.J. 2001. Bovine viral diarrhea virus types 1 and 2 antibody response in calves receiving modified live virus or inactivated vaccines. Vaccine 19:264-274.

Fulton R.W., Ridpath J.F., Confer A.W., Saliki J.T., Burgue L.J. \& Payton M.E. 2003a. Bovine viral diarrhoea virus antigenic diversity: impact on disease and vaccination programmes. Biologicals 31(2):89-95.

Fulton R.W., Saliki J.T., Burge L.J. \& Payton M.E. 2003b. Humoral immune response and assessment of vaccine virus shedding in calves receiving modified live virus vaccines containing bovine herpesvirus-1 and bovine viral diarrhea virus 1a. J. Vet. Med. 50:31-37.

Hamers C., Di Valentin E., Lecomte C., Lambot M., Joris E., Genicot B. \& Pastoret P.P. 2002. Virus neutralizing antibodies against 22 bovine viral diarrhoea virus isolates in vaccinated calves. Vet. J. 163:61-67.

Houe H. 2003. Economic inpact of BVDV infections in dairies. Biologicals 31(2)137-143.

Kreutz L.C., Donis R., Gil L.H.V.G., Lima M., Hoffman A.N., Garcez D.C.P., Flores E.F. \& Weiblen R. 2000. Production and characterization of monoclonal antibodies to Brazilian isolates of bovine viral diarrhea virus. Braz. J. Med. Biol. Res. 33(12):1459-1466.

Lindenbach B.D. \& Rice C.M. 2001. Flaviviridae: the viruses and their replication. Cap.32, p.991-1042. In: Knipe D.M. \& Howley P.M. (ed.) Fields Virology. Lippincot Williams \& Wilkins, Philadelphia.

Oirschot J.T. van, Bruschke C.J.M. \& Rijn P.A. van 1999. Vaccination of cattle against bovine viral diarrhoea. Vet. Microbiol. 64:169-183.

Oliveira L.G., Oliveira E.A.S. \& Silva L.H.T. 1996. Presença de pestivírus e anticorpos contra pestivírus em soros e cultivos celulares. Arq. Bras. Med .Vet. Zootec. 48:513-521.

Reed L. \& Müench H.A. 1938. A simple method of estimating fifty percent endpoints. Am. J. Hyg. 18:493-494.

Ridpath J.F., Bolin S. \& Dubovi E. 1994. Segregation of bovine viral diarrhea virus into genotypes. Virology 205:66-74.

Ridapth J.F. \& Bolin S.R. 1995. Delayed onset postvaccinal mucosal disease as a result of genetic recombination between genotype 1 and genotype 2 BVDV. Virology 212:259-262.

Ridpath J.F. 2003a. BVDV genotypes and biotypes: practical implications for diagnosis and control. Biologicals 31:127-131.

Ridpath J.F. 2003b. Introduction to detecting and controlling BVDV infections. Biologicals 31(2):87.

Scherer C.F.C., Flores E.F., Weiblen R., Caron L., Irigoyen L.F., Neves J.P. \& Maciel M.N. 2001. Experimental infection of pregnant ewes with bovine viral diarrhea virus type-2 (BVDV-2): effects on the pregnancy and fetus. Vet. Microbiol. 77:285-299.

Thrusfield M. 1986. Veterinary Epidemiology. Chap.16: Serological epidemiology. Butterworth, London, p.175-185.

Vilcek S., Paton D.J., Durkovic B., Strojny L., Ibata G., Moussa A., Loitsch A., Rossmanith W., Veja S., Scicluna M.T. \& Paif V. 2001.. Bovine viral diarrhea virus genotype 1 can be separated into at least eleven genetic groups. Arch. Virol. 146(1):99-115.

Vogel F.S.F., Flores E.F., Weiblen R., Mayer S.V., Quadros V.L. \& Oldoni I. 2002. Magnitude, duração e especificidade da resposta sorológica em bovinos vacinados contra o vírus da Diarréia Viral Bovina. Ciência Rural, Santa Maria, 32(1):83-89.

Zimmer G.M., Wentink G.H., Bruschke C., Westenbrink, F.., Brinkhof J. \& de Goey I. 2002. Failure of foetal protection after vaccination against an experimental infection with bovine virus diarrhea virus. Vet. Microbiol. 89:255-265. 